\title{
EFFICACY OF CONTINUOUS INFRACLAVICULAR BRACHIAL PLEXUS BLOCK IN POSTOPERATIVE PAIN CONTROL AFTER UPPER EXTREMITY ORTHOPAEDIC SURGERY
}

\author{
Shabeel Aboobacker1, Aarti Balakrishnan², Syed Fazal Mahmood ${ }^{3}$, S. Padmanabha4 \\ 1 Junior Resident, Department of Anaesthesia, Yenepoya Medical College, Mangalore. \\ ${ }^{2}$ Senior Resident, WIMS, Wayanad. \\ ${ }^{3}$ Post Graduate, Department of Anaesthesia, Yenepoya Medical College, Mangalore. \\ ${ }^{4} H O D$, Department of Anaesthesia, Yenepoya Medical College, Mangalore.
}

\section{ABSTRACT}

This study was aimed to assess the efficacy of patient controlled analgesia using continuous infraclavicular brachial plexus in upper limb surgeries, to study the amount of rescue analgesics used and to study the associated complications and sleep disturbances in patients underwent upper extremity orthopaedic surgery.

\section{MATERIALS AND METHODS}

A prospective randomized clinical study was done on 60 patients undergoing upper limb below mid shaft of humerus surgeries. Sixty patients belonging to ASA-Physical status 1-2 were selected for study and randomly allocated to two groups of 30 each. Group A received patient controlled analgesia with continuous infusion of $0.2 \%$ ropivacaine through infraclavicular catheter (P Group). Group B received patient controlled analgesia with continuous infusion of $0.9 \%$ normal saline through infraclavicular catheter $(C$ Group).

\section{RESULTS}

Patients received ropivacaine experienced significantly less postoperative pain compared with patients received normal saline during rest at all-time intervals except at the baseline. Patients in the C group received first top-up in 5-6 hours, whereas 6 patients in the P group received their first top-up after 10 hours and 22 patients received after 12 hours. In the Group P, patients experienced no sleep disturbances compared to the placebo group.

\section{CONCLUSION}

This randomized, double-blinded, placebo-controlled study shows us that postoperative analgesia is achievable using a perineural infusion of ropivacaine via an infraclavicular brachial plexus catheter after moderately painful upper extremity surgery. Hence, patients experienced a significant decrease in sleep disturbances, analgesic use and narcotic-related side effects.

\section{KEYWORDS}

Ropivacaine, Infraclavicular Brachial Plexus Block, Post-Operative Pain, Regional Anaesthesia.

HOW TO CITE THIS ARTICLE: Shabeel Aboobacker, Aarti Balakrishnan, Syed Fazal Mahmood, S. Padmanabha. "Efficacy of Continuous Infraclavicular Brachial Plexus Block in Postoperative Pain Control after Upper Extremity Orthopaedic Surgery." Journal of Evolution of Medical and Dental Sciences 2015; Vol. 4, Issue 99, December 10; Page: 16464-16469,

DOI: $10.14260 /$ jemds/2015/2443

\section{INTRODUCTION}

Regional anaesthesia has seen a dramatic upsurge since last decade due to advancement in real time imaging techniques, which has led to high success rate and patient safety. Brachial plexus block is indicated for upper extremity surgery and many techniques are available. The key to success depends on the accuracy of needle placement and placement of right amount of local anaesthetic in right concentration and spread of local anaesthetic around the nerve in right fashion. Most of the techniques of nerve localization rely on surface anatomical landmarks for estimating brachial plexus location.

However, at the time of needle insertion, the search for target nerves remains blind. This nerve localization can be frustrating and time consuming with various side effects with lot of patient discomfort and long procedure times.

Most often block failures result from imprecise needle placement and even in experienced hands the failure rate can

Financial or Other, Competing Interest: None.

Submission 11-11-2015, Peer Review 12-11-2015,

Acceptance 02-12-2015, Published 10-12-2015.

Corresponding Author:

Dr. Syed Fazal Mahmood

Department of Anaesthesia,

Yenepoya Medical College,

Mangalore.

E-mail: lazaf4u@gmail.com

DOI:10.14260/jemds/2015/2443 be as high as $10 \%-15 \% .{ }^{1}$ In recent years, there has been growing interest in the development of ultrasound guided brachial plexus blocks. Fluoroscopy is another option.2,3 but its usefulness is limited to visualization of bony landmarks and contrast dye spread near to the neurovascular bundle within the plexus sheath. Ultrasound on the other hand is non-invasive, easily available (Portable) and reproducible. More than $40 \%$ of patients undergoing orthopedic procedures will experience moderate-to-severe postoperative pain. Single-injection of infraclavicular brachial plexus block provides an average of 12-14 hours of analgesia after procedures.

After block resolution, patients usually depend on intravenous or oral narcotics and other drugs to control pain. But narcotics are associated with side effects such as nausea, vomiting, sedation and pruritus. Continuous block with catheter is in since 1940s. It is usually obtained by placing and securing a catheter in the vicinity of the nerves of the brachial plexus by catheter over and through the needle method.

Patient controlled analgesia also called PatientControlled Regional Analgesia (PCRA) is a method of pain control that gives the patient the power to control their pain. A steady state of analgesia is easily obtained by the frequent use of small boluses. In some cases, the pump is set to deliver a small constant flow of pain medication. Additional doses of medications can be self-administered as needed by having the 
patient press a button. Other times the patient can control when he or she receives pain medication and does not receive a constant flow.

Previous investigations done on hospitalized patients suggest that local anesthetic, which is infused via perineural catheters decreases postoperative pain and narcotic requirements. Although perineural infusions have been studied in several series of patients, their efficacy has not been studied in a randomized placebo-controlled manner.

\section{METHODS}

After obtaining ethical committee approval and informed written consent, 60 patients of age between 18-60 years of ASA 1-2 scheduled for upper limb below midshaft of humerus surgeries. Patients aged between 18-60 years, ASA I-II, Body Mass Index (BMI) between $20-25 \mathrm{~kg} / \mathrm{m}^{2}$ and posted for elective surgeries were included in this study and patients with bleeding disorders, narcotic dependence, cervical spine deformities, restricted neck movements, H/o hypersensitivity to local anesthetic, coagulation disorders, known hepatic or renal insufficiency, peripheral neuropathy, lack of patient consent were excluded. Prospective, randomized, 2-arm study on 60 patients who are selected for study were randomly allocated to two groups of 30 each: Group A: Patients received patient controlled analgesia with continuous infusion of $0.2 \%$ ropivacaine through infraclavicular catheter (P Group).

Group B: Patients received patient controlled analgesia with continuous infusion of $0.9 \%$ normal saline through infraclavicular catheter (C Group). Preanaesthetic checkup done and an informed consent was taken from the patient. Patients premedicated with Tab. Alprazolam $0.25 \mathrm{mg}$ and Tab. Ranitidine $150 \mathrm{mg}$ on the previous night of surgery and asked to be nil per orally from the midnight of the previous day of surgery. On the day of surgery after shifting the patient to the OT, an intravenous cannula will be placed and ringer lactate started. After arrival in the pre-anaesthetic area, the patients will be given Inj. Metoclopramide $10 \mathrm{mg}$ IV $1 \mathrm{hr}$. before induction and Inj. Glycopyrrolate $0.2 \mathrm{mg}$ with Inj.

Midazolam $1.5 \mathrm{mg}$ IV non-invasive monitors like the NIBP, ECG and $\mathrm{SpO}_{2}$ were connected and the patient explained about the whole procedure once again. Inj. Fentanyl 50mcg IV given and 4L oxygen through mask administered. After sterile preparations and draping with patient in supine position and operating limb by the patient side, a nerve stimulator and a $20 \mathrm{G}$ insulated stimulating needle were used to place a vertical infraclavicular brachial plexus block. A skin wheal of $2 \mathrm{~cm}$ was raised below the midpoint of the clavicle between the jugular notch and the ventral acromion with $2 \%$ plain xylocaine.

The needle was inserted through this skin wheal with bevel towards the patient head and directed ventral to dorsal strictly in the sagittal plane with absolutely no medial angulation with continuous aspiration and nerve stimulator initially set at $1.2 \mathrm{~mA}$. Usually, the plexus will be encountered at a depth of $2.3 \mathrm{~cm}$, if not identified even after $5 \mathrm{~cm}$ then the needle will be withdrawn to the skin and redirected caudally until discrete stimulated motion occurs in any of the four digits with a current between 0.30 and $0.55 \mathrm{~mA}$. For block $35 \mathrm{ml}$ of $0.2 \%$ ropivacaine should be injected after which a 20G catheter will be passed through this needle and secured with a sterile dressing after removing the needle completely.

Patients was withdrawn from the study if the block failed or if the catheter gets placed in a vessel and the block was converted to general anesthesia. After a successful block and catheter placement, patients was assigned to receive either a $0.2 \%$ ropivacaine infusion or a saline infusion. Postoperatively, after 6 hours PCA infusion pump containing study solution was connected to the catheter with a continuous infusion of $8 \mathrm{ml} / \mathrm{hr}$ and a patient controlled bolus of $2 \mathrm{ml}$ available every $20 \mathrm{~min}$.

Pain, by using a VAS ranging from $0=$ no pain to $10=$ worst pain imaginable, will be assessed at the time when PCIA or PCA will be started in the recovery room $(t=0)$ and every $6 \mathrm{hr}$. for the next $48 \mathrm{hr}$. The appearance of nausea, vomiting, pruritus or other side effects was noted. The time of the first PCA bolus was checked. Nausea and pruritus will be recorded only when patients asked for treatment. Nausea was treated by $4 \mathrm{mg}$ Ondansetron given intravenously and pruritus was treated using 10 or $20 \mathrm{mg}$ propofol given intravenously and repeated as necessary.

A motor block was considered present when the patient reported difficulties in flexing or extending any of the fingers $12 \mathrm{hr}$. after the block. Patient satisfaction assessed 6hr. after the end of the study period was evaluated using a VAS ranging from $0=$ not satisfied to $10=$ entirely satisfied. Gross sensory and motor function was reviewed. Patients were also questioned about symptoms of local anesthetic toxicity and the appearance of the catheter site.

\begin{tabular}{|c|c|c|c|c|}
\hline \multicolumn{5}{|l|}{ RESULTS } \\
\hline & \multicolumn{2}{|c|}{$\begin{array}{c}\text { Group C } \\
(n=30)\end{array}$} & \multicolumn{2}{|c|}{$\begin{array}{c}\text { Group P } \\
(n=30)\end{array}$} \\
\hline & No. & $\%$ & No. & $\%$ \\
\hline \multicolumn{5}{|c|}{ Pulse Rate } \\
\hline$<70$ & 2 & 6.7 & 0 & 0.0 \\
\hline $70-100$ & 28 & 93.3 & 30 & 100.0 \\
\hline$>100$ & 0 & 0.0 & 0 & 0.0 \\
\hline \multicolumn{5}{|c|}{ SBP (mmHg) } \\
\hline$<120$ & 2 & 6.7 & 0 & 0.0 \\
\hline $120-140$ & 28 & 93.3 & 30 & 100.0 \\
\hline$>140$ & 0 & 0.0 & 0 & 0.0 \\
\hline \multicolumn{5}{|c|}{ DBP (mmHg) } \\
\hline$<80$ & 16 & 53.3 & 23 & 76.7 \\
\hline $80-100$ & 14 & 46.7 & 7 & 23.3 \\
\hline$>100$ & 0 & 0.0 & 0 & 0.0 \\
\hline & 0 & two & $\overline{u l s}$ & \\
\hline
\end{tabular}
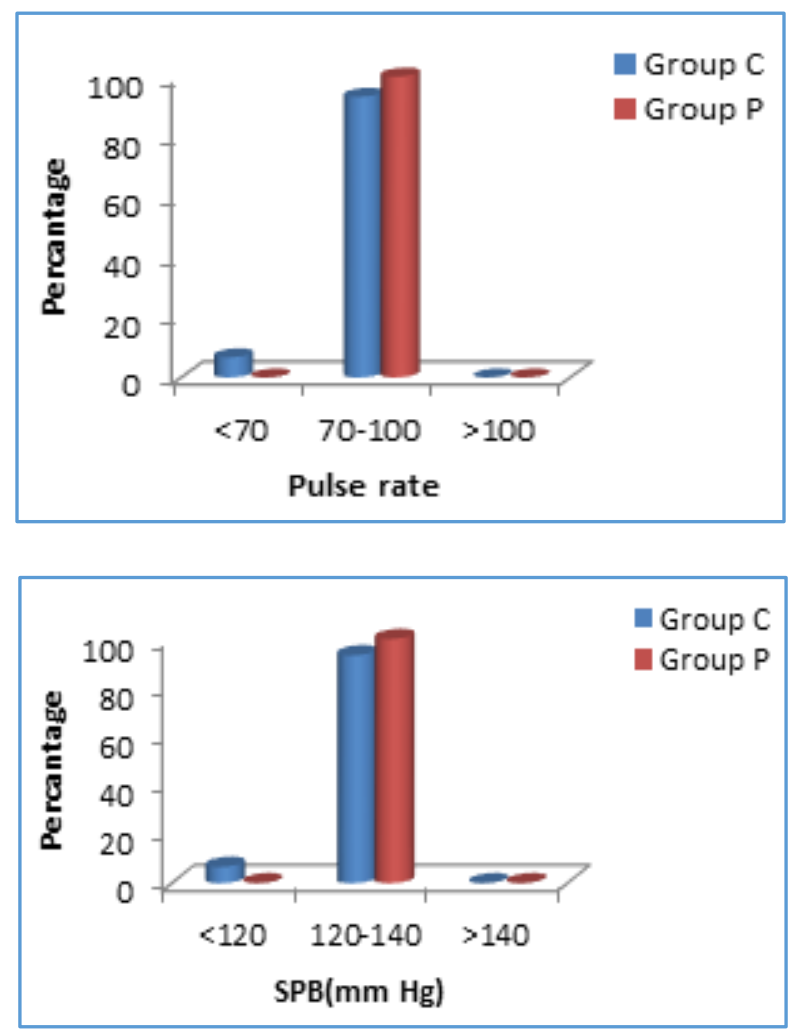


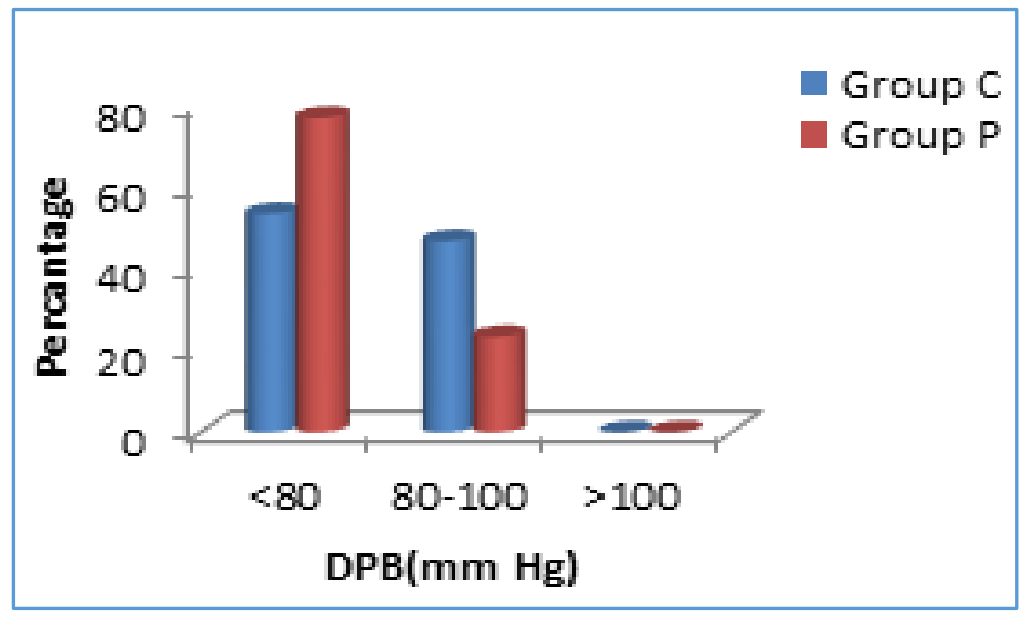

\begin{tabular}{|c|c|c|c|}
\hline & Group C & Group P & P value \\
\hline Pulse rate & $76.40 \pm 4.31$ & $76.93 \pm 3.81$ & 0.614 \\
\hline SBP (mmHg) & $127.93 \pm 6.20$ & $128.60 \pm 5.12$ & 0.652 \\
\hline DBP (mmHg) & $77.00 \pm 7.40$ & $74.60 \pm 6.20$ & 0.179 \\
\hline \multicolumn{3}{|c|}{ Table 2: Comparison of Pulse Rate, SBP and } \\
DBP in two groups studied \\
\hline
\end{tabular}

\begin{tabular}{|c|c|c|c|}
\hline Pain Score & Group C & Group P & P value \\
\hline $6 \mathrm{hrs}$ & $0.80 \pm 0.41$ & $0.82 \pm 0.39$ & 0.839 \\
\hline $12 \mathrm{hrs}$ & $2.97 \pm 0.85$ & $1.71 \pm 0.66$ & $<0.001^{* *}$ \\
\hline $18 \mathrm{hrs}$ & $4.13 \pm 0.90$ & $2.32 \pm 0.98$ & $<0.001^{* *}$ \\
\hline $24 \mathrm{hrs}$ & $5.03 \pm 0.67$ & $3.39 \pm 0.83$ & $<0.001^{* *}$ \\
\hline $30 \mathrm{hrs}$ & $5.70 \pm 1.09$ & $3.57 \pm 0.96$ & $<0.001^{* *}$ \\
\hline $36 \mathrm{hrs}$ & $6.27 \pm 0.94$ & $3.46 \pm 0.69$ & $<0.001^{* *}$ \\
\hline $42 \mathrm{hrs}$ & $7.00 \pm 0.87$ & $4.21 \pm 0.63$ & $<0.001^{* *}$ \\
\hline $48 \mathrm{hrs}$ & $8.27 \pm 0.64$ & $4.68 \pm 0.48$ & $<0.001^{* *}$ \\
\hline \multicolumn{4}{|c|}{ Table 3: Pain Score: Comparative } \\
evaluation in two groups studied \\
\hline \multicolumn{4}{|c}{} \\
\hline
\end{tabular}

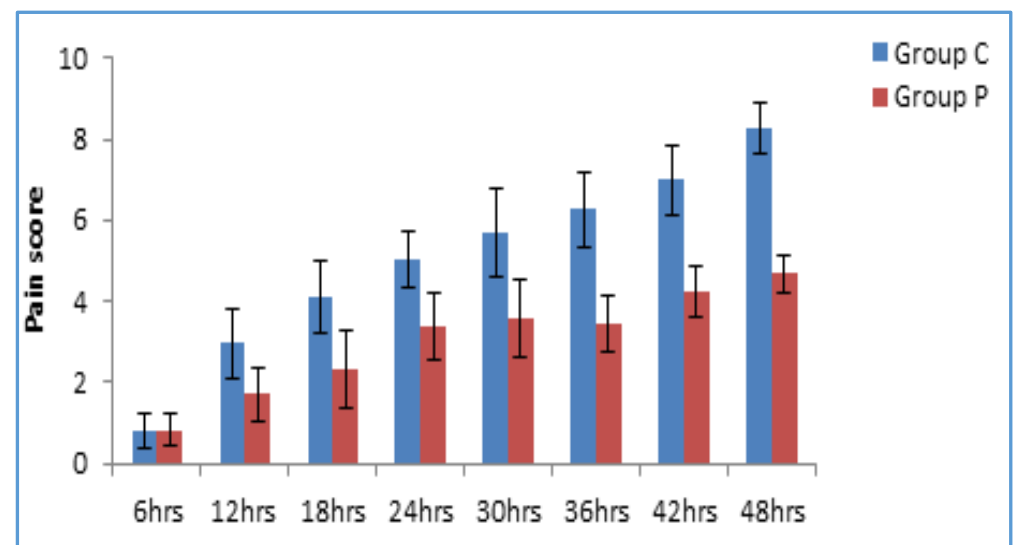

\begin{tabular}{|c|c|c|c|c|}
\hline \multirow{2}{*}{ Sleep Disturbances } & \multicolumn{2}{|c|}{ Group C } & \multicolumn{2}{c|}{ Group P } \\
\cline { 2 - 5 } & No. & $\mathbf{\%}$ & No. & \% \\
\hline General Anesthesia given & 0 & 0.0 & 2 & 6.7 \\
\hline No & 1 & 3.3 & 28 & 93.3 \\
\hline Yes & 29 & 96.7 & 0 & 0.0 \\
\hline Total & 30 & 100.0 & 30 & 100.0 \\
\hline Table 4: Sleep disturbances of patients \\
in two groups studied \\
\hline
\end{tabular}

$\mathrm{p}<0.001^{* *}$, Significant, Fisher Exact test 


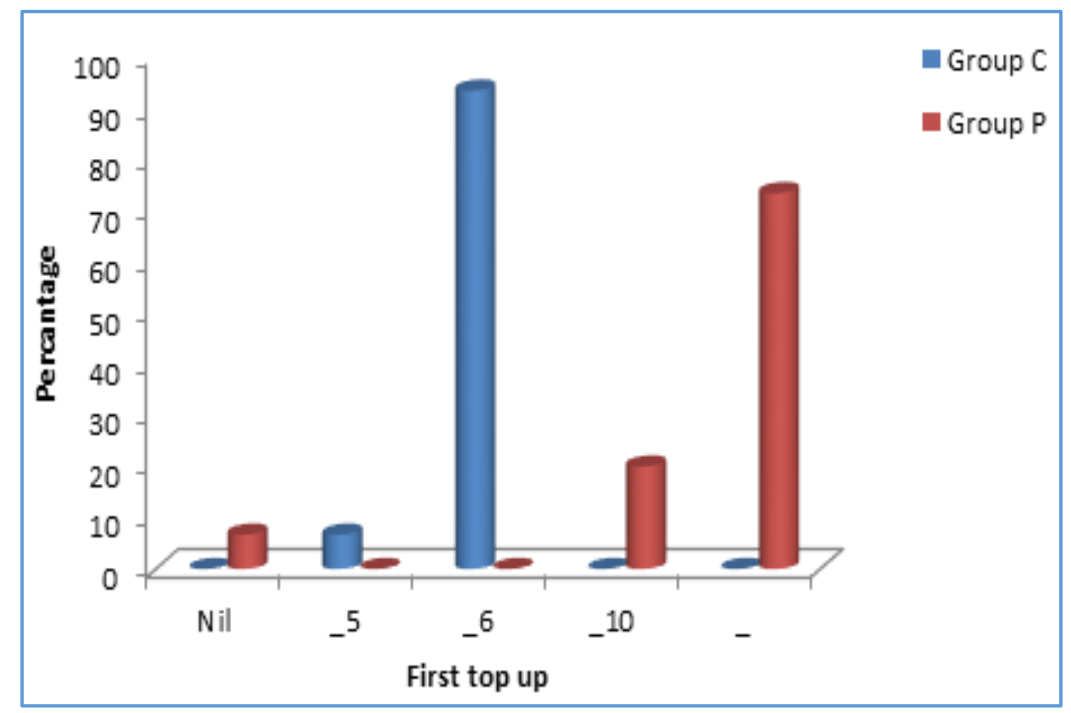

\begin{tabular}{|c|c|c|c|c|}
\hline First Top & \multicolumn{2}{|c|}{ Group C } & \multicolumn{2}{c|}{ Group P } \\
\cline { 2 - 5 } Up & No. & \% & No. & \% \\
\hline Nil & 0 & 0.0 & 2 & 6.7 \\
\hline 5 & 2 & 6.7 & 0 & 0.0 \\
\hline 6 & 28 & 93.3 & 0 & 0.0 \\
\hline 10 & 0 & 0.0 & 6 & 20.0 \\
\hline 12 & 0 & 0.0 & 22 & 73.3 \\
\hline Total & 30 & 100.0 & 30 & 100.0 \\
\hline \multicolumn{3}{|c|}{ Table 5: First top-up of patients in } \\
two groups studied \\
\hline
\end{tabular}

$\mathrm{p}<0.001^{* *}$, Significant, Fisher Exact test

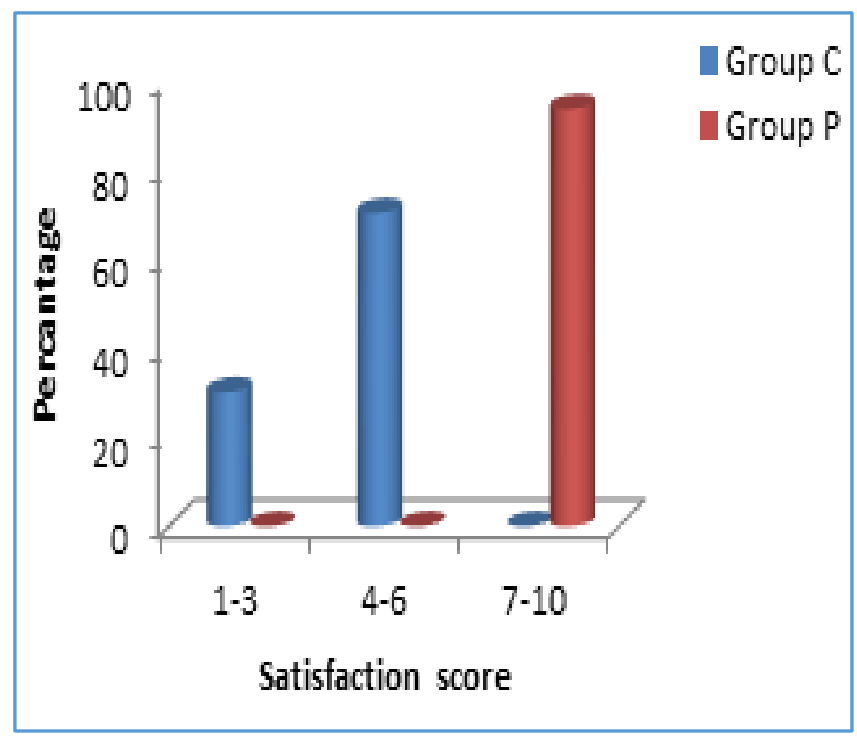

\begin{tabular}{|c|c|c|c|c|}
\hline \multirow{2}{*}{$\begin{array}{c}\text { Satisfaction } \\
\text { Score }\end{array}$} & \multicolumn{2}{|c|}{ Group C } & \multicolumn{2}{c|}{ Group P } \\
\cline { 2 - 5 } & No. & $\mathbf{\%}$ & No. & $\mathbf{\%}$ \\
\hline $1-3$ & 9 & 30.0 & 0 & 0.0 \\
\hline $4-6$ & 21 & 70.0 & 0 & 0.0 \\
\hline $7-10$ & 0 & 0.0 & 28 & 93.3 \\
\hline Total & 30 & 100.0 & 30 & 100.0 \\
\hline Mean \pm SD & \multicolumn{2}{|c|}{$3.70 \pm 0.59$} & \multicolumn{2}{c|}{$7.86 \pm 0.45$} \\
\hline
\end{tabular}

$\mathrm{p}<0.001^{* *}$, Significant, Student ' $\mathrm{t}$ ' test

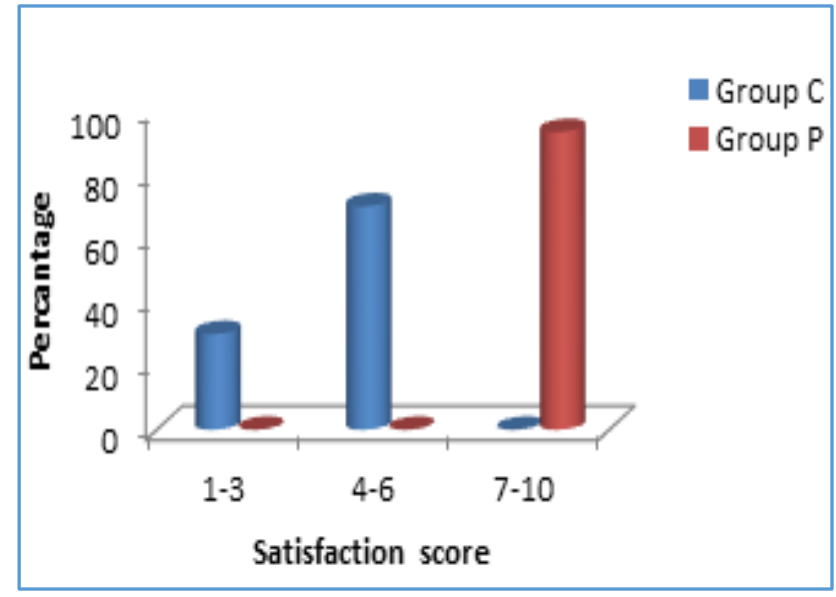

\begin{tabular}{|c|c|c|c|c|}
\hline \multirow{2}{*}{$\begin{array}{c}\text { Adverse } \\
\text { Effects }\end{array}$} & \multicolumn{2}{|c|}{ Group C } & \multicolumn{2}{c|}{ Group P } \\
\cline { 2 - 5 } & No. & \% & No. & \% \\
\hline Yes & 0 & 0.0 & 0 & 0.0 \\
\hline No & 30 & 100.0 & 28 & 100.00 \\
\hline Total & 30 & 100.0 & 28 & 100.0 \\
\hline \multicolumn{4}{|c|}{ Table 7: Adverse Effects } \\
\hline
\end{tabular}

$\mathrm{p}=1.000$, Not significant, Fisher Exact test

Sixty patients were approached for study inclusion and all chose to be enrolled. All patients of either sex belonging to ASA I and ASA II had an infraclavicular block placed successfully. Sixty patients were randomized to receive either Ropivacaine $(n=30)$ or placebo $(n=30)$ infusion. There were no statistically significant differences between these groups in demographics, intravenous sedation for block placement, tourniquet and surgical duration or surgical procedures. Two patients in group P were given general anaesthesia as the block did not work. All the patients were hemodynamically stable all through the procedure and in the postoperative period (Table 5). Patients receiving ropivacaine (Group P) experienced significantly less postoperative pain compared with patients receiving normal saline (Group C) during rest (Table 6) at all-time intervals except at the baseline.

Patients in the ( $\mathrm{C}$ group): Saline group received first top in 5-6 hours, whereas 6 patients in the (P group) ropivacaine group received their first top-up after 10 hours and 22 patients received after 12 hours. In the ropivacaine group, (Group P) patients experienced no sleep disturbances compared to the placebo group (Table 7) and patients 
received significantly fewer acetaminophen 1 gram infusions -2.39 at $24 \mathrm{hrs}$. and 3.46 at $48 \mathrm{hrs}$. to remain comfortable (Table 11). The average satisfaction with postoperative analgesia on a scale of 0 (dissatisfied) to 10 (very satisfied) was ranked $7.86 \pm 0.45$ by those who received ropivacaine and $3.7 \pm 0.59$ by those who received placebo $(p \leq 0.001)$. There were no apparent local anesthetic- or catheter-related complications during infusion. All catheters remained in situ throughout the study period.

Patients used mechanical infusion pumps without difficulty. The only complaint consistently noted by patients (roughly 5\%) was leakage of clear fluid from under the occlusive dressing. In addition one infusion pump had to be replaced on the morning of postoperative day 1 , when it alarmed continuously without apparent cause. The biomedical engineer rectified it.

\section{DISCUSSION}

This approach to the brachial plexus was chosen for several reasons. Unlike axillary placement, the initial nerve block and postoperative infusion reliably provide anesthesia and analgesia to the musculocutaneous nerve with a single injection and catheter. Further, catheters in this location are more comfortable for patients and resistant to dislodgement compared with an axillary placement. This randomized, double-blinded, placebo-controlled study shows us that postoperative analgesia is achievable using a perineural infusion of ropivacaine via an infraclavicular brachial plexus catheter after moderately painful upper extremity surgery. Hence, patients experienced a significant decrease in sleep disturbances, analgesic use and narcotic-related side effects. These benefits were attained with the use of a PCRA-capable infusion pump. There were no local anaesthetic drug related side effects in our study.

\section{Infraclavicular Approach and Techniques}

Initially, described by Whiffler. ${ }^{4}$ and later by Wilson. ${ }^{5}$ the coracoid technique has been used in many studies for several reasons. It is simple to perform. ${ }^{6}$ has a high success rate and theoretically reliably places the catheter tip at the level of the brachial plexus cords. By keeping the length of the needle exclusively in the paramedian sagittal plane, the needle tip is not directed toward the lung. Important disadvantage of the coracoid technique is the $90^{\circ}$ angle, at which the brachial plexus is contacted by the needle, making catheter insertion difficult. Just proximal to the coracoid process, the brachial plexus cords surround the axillary artery. With the catheter insertion system we used, when the relatively stiff catheter tip was advanced past the needle tip, the catheter often penetrated the vessel. In our patients in the modified technique, when resistance was encountered and the catheter reached the needle tip, the catheter was held securely in place while the needle was withdrawn over the catheter. This approach left the catheter tip at the original location of the tip of the needle and there were no instances of intravascular catheter placement in our study.

Chin, Ki Jinn; Singh, Mandeep; Velayutham, Veerabadran; Chee, Victor. ${ }^{6}(2010)$ also concurred that ICB is a safe and simple technique for providing surgical anaesthesia of the lower arm with an efficacy comparable to other BPBs. The advantages of ICB include a lower likelihood of tourniquet pain during surgery and more reliable blockade of the musculocutaneous and axillary nerves when compared to a single-injection axillary block.7,8 The efficacy of ICB is likely to be improved if adequate time is allowed for block onset (At least 30 minutes) and if a volume of at least $40 \mathrm{ml}$ is injected. Ponde VC has described a modified technique of continuous infraclavicular brachial plexus block. A modified technique for continuous infraclavicular brachial plexus block helps secure the catheter and provides effective intra- and postoperative pain relief in pediatric patients. We used this technique in our study and found it to be practical.

The advantages of infraclavicular blocks are the ability to perform the block with the ipsilateral arm in any position and the presence of a consistent palpable bony landmarks that are palpable easily even in the obese patients. The infraclavicular brachial plexus block provides dense anesthesia in the same regions as the supraclavicular block (upper arm, elbow, forearm and hand). However, it avoids the risk of phrenic nerve block, making it an excellent choice in those patients with respiratory issues. This block gives excellent results with $91 \%$ of patients having analgesia of 5 terminal nerves distal to the elbow, so this single injection is time efficient.

The infraclavicular approach described makes it possible to tolerate the arm tourniquet without the need of additional infiltration, minimization of the risk of pneumothorax, and can be given in case of burns involving supraclavicular area. Also bilateral infraclavicular block can be given when indicated. The only disadvantage is the inability to externally compress the source of hematoma if vessel is punctured.

Technique: Local Anaesthetics and Volume of Local Anaesthetics

The nerve stimulator-guided infraclavicular technique usually requires a relatively high volume of local anesthetic for better result. For longer anesthesia/analgesia $30 \mathrm{ml}$ of $0.5 \%$ ropivacaine or bupivacaine can provide more than 12 hours of anesthesia, although the onset is delayed to 20-30 min. For the initial surgical block, Ropivacaine was used because this offers $4-5 \mathrm{hr}$. of surgical anesthesia. For postoperative analgesia, ropivacaine was used because it produces less motor impairment than bupivacaine during a continuous perineural infusion, while providing equipotent sensory analgesia. ${ }^{9}$ We have also found that after infusion discontinuation, the anesthetic and analgesic duration of ropivacaine is less than bupivacaine. In addition, its safety in patients without renal or hepatic failure has been demonstrated.

\section{PCRA}

Patient Controlled Analgesia (PCA) is a method of pain control designed to allow the patient to administer preset doses of an analgesic on demand. Although the medications may be delivered via any route, for the purpose of this position statement the term refers to medications which are administered using an analgesic infusion pump. Analgesic infusion pump (Often referred to as PCA pump) is an electronic microprocessing machine, which can be programmed to deliver a prescribed amount of medication on demand at specified intervals by activation (pressing) of a button. It also has the programming options to deliver patient boluses along with a continuous infusion or a continuous infusion without patient boluses (Thus contradicting the term "PCA" pump. In our study, we used syringe pump with PCA programmable capability.

We counselled the patients in the preoperative period and before starting the procedure as regards the use of the pump. All the patients except two in whom GA was supplemented used the pumps without difficulty. As it was inpatient setup, the nurses and on-call doctors were available for any clarifications and other health care issues. We used $0.2 \%$ Ropivacaine in the study group and normal saline in the placebo group with a continuous infusion of $8 \mathrm{ml} / \mathrm{hr}$ and a patient controlled bolus of $2 \mathrm{ml}$ available every $20 \mathrm{~min}$. In our study, patients experienced a significant decrease in sleep 
disturbances and analgesic use. The degree of analgesia, the longer duration of analgesia, patient participation in controlling their pain and proper counseling of patients about the system have led to a high rate of satisfaction.

\section{Postoperative Analgesia}

Because postoperative pain waxes and wanes over time and often increases with movement, an infusion pump that combines a basal infusion rate with a patient-controlled bolus function is desirable to manage break-through pain and minimize motor block. In this investigation, patients receiving ropivacaine by infusion with PCRA reported on average minimal-to-no pain at rest until their catheters were removed the evening of postoperative day 2. In contrast, patients receiving placebo infusions were unable to achieve this degree of comfort using acetaminophen. We conclude that perineural ropivacaine infusion significantly decreased patient's break-through pain at rest.

Consistent with the improved analgesia in the ropivacaine group, there was a significant decrease in paracetamol consumption and side effects for patients receiving ropivacaine compared with those receiving placebo (Table 11).

\section{Study Limitations}

A potential drawback of this study design is that patients receiving a saline infusion may have had their initial regional block duration shortened from a "wash out" effect, as has been described for epidural anesthesia. However, the time from block placement until initial analgesic use for patients in the placebo group was in our experience, comparable with patients receiving single-injection infraclavicular blocks for similar procedures.

\section{CONCLUSION}

This randomized, double-blinded, placebo-controlled study shows us that postoperative analgesia is achievable using a perineural infusion of ropivacaine via an infraclavicular brachial plexus catheter after moderately painful upper extremity surgery. Hence, patients experienced a significant decrease in sleep disturbances, analgesic use and narcoticrelated side effects. These benefits were attained with the use of a PCRA-capable infusion pump. There were no local anaesthetic drug related side effects in our study. The degree of analgesia, the longer duration of analgesia, patient participation in controlling their pain and relative simplicity of the system might have led to a high rate of satisfaction for all subjects receiving Ropivacaine.

\section{REFERENCES}

1. Sia S, Bartoli M, Lepri A, Marchini O. Multiple injection axillary brachial plexus block: A comparison of two methods of nerve localization: nerve stimulation versus paraesthesia. AnesthAnalg 2000;91:647-51.

2. Wong GY, Brown DL, Miller GM, Cahill DR. Defining the cross-sectional anatomy important to interscalene brachial plexus block with magnetic resonance imaging. RegAnesth Pain Med 1998;23:77-80.

3. Mukherji S, Wagle A, Armao D. Brachial plexus nerve block with CT guidance for regional pain management. Radiology 2000;216:886-90.

4. Wilson JL, Brown DL, Wong GY, Ehman RL, Cahill DR: Infraclavicular brachial plexus block: parasagittal anatomy important to the coracoid technique. AnesthAnalg 1998;87:870-3.

5. Whiffler K: Coracoid block-a safe and easy technique. Br J Anaesth 1981;53:845-8.

6. Chin KJ, Singh M, Velayutham V, Chee V. Infraclavicular brachial plexus block for regional anaesthesia of the lower arm. Victor Anaesthesiology 2010.

7. Perlas A, Chan VW, Simons M, Nishiyama M, Naganuma $\mathrm{K}$, Amaki Y. A new approach for brachial plexus block under fluoroscopic guidance. AnesthAnalg 1999;88:91-7.

8. Fink BR. History of neural blockade. In: Cousins MJ, Bridenbaugh PO (eds): Neural Blockade, $2^{\text {nd }}$ ed. London, JB Lippincott, 1988 pp 3-21.

9. Perlas A, Chan V, Simons M. Brachial plexus examination and localization using ultrasound and electrical stimulation: a volunteer study. Anesthesiology 2003;99:429-35. 